Journal of Qualitative Criminal Justice \& Criminology

\title{
Gate Keeping and the Politics of Access to Prisons: Implications for Qualitative Prison Research
}

Janani Umamaheswar ${ }^{1}$

${ }^{1}$ Rider University

Published on: Oct 01, 2014

DOI: 10.21428/88de04a1.a0f03b64

License: Creative Commons Attribution 4.0 International License (CC-BY 4.0). 


\begin{abstract}
In this article, I draw on and contribute to existing literature on reflexivity and access in qualitative research, specifically in the context of prison research. I do this through a critical discussion of the research process involved in conducting a study on women prisoners in the U.S. In addition to describing the obstacles I faced in gaining access to a research site in which to conduct the study, I also discuss the implications of gate keeping for knowledge produced about women prisoners. Finally, I build on Bosworth et al.'s (2005) discussion of prison research using communication by mail. I argue that mail correspondence with inmates is a helpful way of obtaining rich data while surmounting some of the difficulties involved in conducting prison research.
\end{abstract}

\title{
Introduction
}

Qualitative researchers have devoted considerable attention to issues related to reflexivity in the research process, and they have also discussed the political considerations involved in conducting qualitative research (Christians, 2005; Newman; 1958; Punch, 1994). Politics infuses every social science research project to a lesser or greater extent. Politics here refers to "everything from the micropolitics of personal relations to ... the powers and policies of government research departments, and ultimately even that hand (heavy or otherwise) of the central state itself" (Punch, 1994, p. 84). In this article, I employ this definition of politics to focus on the "powers and policies" of state actors in their roles as gatekeepers in prison research.

There are difficulties inherent in prison research that are absent in most other qualitative research studies (Bosworth, Campbell, Demby, Ferranti, \& Santos, 2005; Schlosser, 2008). Qualitative prison studies were quite common in the mid-20th century (Giallombardo, 1965; Heffernan, 1972; Sykes, 1958; Ward \& Kassebaum, 1965), a time considered to be the heyday of prison sociology. Since then, however, such research has become very rare, a result both of more stringent Institutional Review Board (IRB) control of research projects and the administrative difficulties involved in entering prisons as research sites (Bosworth et al., 2005).

In addition to prisoners being considered vulnerable by IRB standards (Schlosser, 2008), prisons are designed to separate inmates from the rest of society. Outsiders in the prison environment are thus often met with mistrust by both staff and inmates (Bosworth et al., 2005; Newman, 1958). As a result, qualitative studies on prison populations have become more infrequent than they were in the 50s and 60s. Conducting qualitative prison research has become particularly difficult because of the sheer number of steps the researcher must undertake before the study can begin. These steps include satisfying the demands of educational IRBs, state departments of corrections (DOCs), and prison officials. For researchers who are early in their careers and must keep to a tight timeline in their 
production of scholarly work, prison fieldwork is an especially daunting project. Although the final onset of the research study may come as a relief to the researcher, the steps he/she takes to gain access to prisons must be examined reflexively. This is important in understanding how the politics of gaining access to prison facilities affect who is studied, what questions may be asked, and how the study proceeds.

Much of the research on prisons is now being "conducted from afar" (Simon, 2000 p. 289) through journalism and official reports or by researchers using quantitative datasets rather than through qualitative fieldwork in prison facilities. Understanding the lived experiences of inmates, however, remains an important goal because they represent an especially disadvantaged and high-risk group of offenders (Moloney, Ven den bergh, \& Moller, 1999) whose experiences in prison have reverberating consequences throughout their life course (Pettit \& Western, 2004). Yet it is precisely these prison experiences that researchers are unable to study because of the difficulties involved in accessing prisons as research sites (Kruttschnitt \& Gartner, 2003). While some of the reasons behind the scarcity of qualitative prison research may be clear, the implications of gate keeping are important in assessing the state of our knowledge about prison populations, since this is shaped in part by which inmates we are granted access to study and why.

This article has two primary goals: 1 . To shed light on the political considerations that prison researchers can expect to confront when proposing fieldwork in prisons, especially in the U.S.; and 2. to highlight the epistemic implications of these considerations. In addition to building on discussions of the challenges that prison researchers face (Bosworth et al., 2005; Schlosser, 2008), I describe the consequences of gate keeping for what we are able to learn about women prisoners in the U.S. In so doing, I emphasize that the politics involved in gaining (and maintaining) access to prisons exemplify how "fieldwork ... represents a demanding craft that involves both coping with multiple negotiations and continually dealing with ethical dilemmas" (Punch, 1994, p. 85).

This article is organized as follows: After reviewing relevant literature on reflexivity and access in qualitative research, I describe my attempts to gain access to prisons in two different states. Here, I highlight the reasons why the research study was rejected by one of these states. I then build on Bosworth et al. (2005)'s discussion of prison research by mail communication, emphasizing the benefits of this methodology in an era when access to prisons is extremely difficult to gain and maintain. Throughout the article, I discuss the implications of the politics of gate keeping for knowledge produced about women prisoners, especially in the context of qualitative research.

\section{Literature review}




\section{Reflexivity in qualitative research}

Reflexivity in the social sciences emerged in the 1970s as a response to scholars' criticisms of research that purported to be objective and that paid little regard to researchers' subjectivity. Prior to this, the researcher was invisible both during the research process and later as a writer (Goodwin \& Horowitz, 2002). While some scholars argued that it was impossible to understand a situation fully without being involved in it, others believed that involvement of the researcher compromised the objectivity of the research findings (Goodwin \& Horowitz, 2002). Reflexivity has now become a key methodological skill that qualitative researchers use to demonstrate the legitimacy and trustworthiness of their research (Pillow, 2006).

Reflexivity in qualitative research is often understood in terms of an awareness of research subjectivity: "a focus on how does who I am, who I have been, who I think I am, and how I feel affect data collection and analysis" (Pillow, 2006, p. 176). For instance, Bourdieu (2002) highlighted the importance of conducting the sociology of sociology. By this, he meant that researchers should not see themselves as passive, outside constructers of theory. Instead, they must be aware of the effects of their own gaze on their research. Because the meaning that researchers find in interviews intersect with their own identities (Warren, 2001), some scholars have argued that a "contamination" of research with one's own lived experiences results in a rich, complex understanding of the phenomenon under investigation (Ellingson, 1998, p. 494; Krieger, 1985).

Reflexivity thus occurs when a researcher does not simply report facts or truths, but also engages in a continuous process of self-reflection (Hertz, 1996). Throughout this process, the researcher actively constructs interpretations of his/her experiences in the field (Hertz, 1996). However, as Pillow (2006) noted, defining and describing the requirements of reflexivity is a difficult task. One issue lies in the question of about whom or what researchers should be reflexive: Should researchers be reflexive about themselves? Their participants? The research process? Reflexivity also encapsulates the questions that researchers must ask about the politics of representation insofar as whom the researchers represent and what is represented is shaped in part by the research process itself (Pillow, 2006). While some researchers have argued that the recent trend in increased self-reflexivity is overly self-indulgent, I, like Spivak (1984-1985, p. 184), believe that it is important to be "vigilant about our practices."

Although reflexivity has most often been understood as the process by which the researcher examines how his/her own biography affects the research process, researchers' claims also depend on how knowledge is acquired and interpreted (Altheide \& Johnson, 1998). There are three different forms of reflexivity, according to Wacquant (2011, p. 441): 1. egological or narcissistic, where the focus is on the person of the researcher (as described above); 2. textual, where the researcher examines the rhetoric 
she deploys in her analyses; and 3. epistemic, where the focus is on "dissecting the social conditions and techniques of production of the scientific project."

In this article, I build on what Wacquant (2011, p. 441) termed 'the political economy of criminological knowledge." I draw on his epistemic definition of reflexivity specifically to assess how the politics of gate keeping affect what kind of prison research it is possible to do, where it is possible to conduct prison research, and with whom such research is possible. As such, this article is geared less toward self-reflexivity and more toward a discussion of reflexivity about the process of doing penological research. As Wacquant (2011, p. 439) points out, reflexivity in criminology is essential because it requires that researchers "think through criminological issues as they relate to politics and policy." My employment of epistemic reflexivity is thus intended to shift the focus away from my role (as the researcher) in the research process and toward the process itself.

Prison scholars have demonstrated the value of transparency by showing a great deal of reflexivity in their discussions of the process of conducting prison research. These scholars have candidly described, for example, how their own political and intellectual beliefs are represented in their data and analyses, and what challenges they encountered during the research process (Bosworth et al., 2005; King \& Liebling, 2007; Liebling, 2001; McCorkel, 1998; Schlosser, 2008). I follow the path set forth by these researchers by emphasizing how gate-keeping issues affect what knowledge is produced about women prisoners. This is particularly important because texts about women prisoners (like other criminological and penological texts) are "conceived, written, diffused (or not) and deployed" (Wacquant, 2011, p. 439) in specific structural conditions that merit more attention than they have thus received from penologists. Specifically, Wacquant recognized that one element that constitutes the structural conditions in which criminological knowledge is produced is the "overt and covert intrusion of the concerns of politicians" (Wacquant, 2011, p. 441). An institutional analysis of the numerous other elements that shape how, why, and for whom criminological knowledge is produced is beyond the scope of this article. As such, I instead critically reflect on the "overt and covert intrusion" not of politicians specifically, but of state actors authorized to grant or block access to inmate populations.

\section{Access and gate keeping}

In addition to issues related to reflexivity, the issue of gate keeping in social science research is one that sociologists generally have been cognizant of for many years now (Broadhead \& Rist, 1976). Qualitative researchers have been especially concerned with how access to research sites is obtained (Duke, 2002), and scholars have devoted considerable attention to the practical considerations involved in gaining access to research sites (Feldman, Belle, \& Berger, 2003; Reeves, 2010). Understanding the issues involved in gaining access to a field site is important not only because it facilitates the commencement of research, but also because "the process of 'getting in' affects what information is available to the researcher" (Feldman et al., 2003, p. vii). 
Gatekeepers are people who "can help or hinder the research depending upon their personal thoughts on the validity of the research and its value" (Reeves, 2010, p. 317). Gatekeepers can be both formal and informal (Reeves, 2010). In prison research, formal gatekeepers include research review committee members at U.S. Departments of Corrections, prison officials, etc. Informal gatekeepers include actors such as correctional officers who cannot officially deny requests to conduct research, but who are instrumental in the research process.

Qualitative researchers have paid a great deal of attention to issues surrounding gatekeepers to research sites generally (Broadhead and Rist, 1976; Reeves, 2010; Smith, 1997; Venkatesh, 2008). These researchers have described at length the negotiations involved in conducting research in sites where access is contingent on approval from either formal or informal gatekeepers. Several decades ago, for instance, Broadhead and Rist (1976) outlined the ways in which gatekeepers control the research process by both limiting access and asserting influence on the scope and goals of the research. Thus, gate keeping is not a novel issue for qualitative researchers.

There continues to be room, however, to develop this literature in the context of prison research specifically (King \& Liebling, 2007; Schlosser, 2008). Prisoners are perhaps the best example of what Emmel, Hughes, Greenhalgh, and Sales (2006) describe as socially excluded people. They are segregated from mainstream society, and women inmates in particular are held in facilities that are often far away from their home communities. Most significantly, inmate populations are managed by state actors who are responsible for maintaining a controlled and regimented environment in their facilities. Emmel et al. noted that in their own research on socially excluded people, gatekeepers played an instrumental role in facilitating access to the participants. Importantly, the extent to which gatekeepers facilitated access was contingent on the relationship of power and trust between the gatekeepers and the participants. The researchers conclude that "a trustful relationship between gatekeeper and participant provides the necessary precondition for the researcher and participant to come to know each other" (Emmel et al., 2006).

In research on prisoners, however, the relationship between gatekeepers (prison officials, for example) and participants (prisoners) is far from trusting, and it is characterized by a rigid power differential. In addition to the difficulties posed by a lack of trust between gatekeepers and researchers, therefore, conducting prison research is also difficult because there exists very little trust between gatekeepers and participants. In this study, for example, my interaction with the correctional officers during a visit to the prison revealed their attitude toward the inmates. As I waited in an office to begin interviewing, a group of male correctional officers entered the room. They asked me what I was researching, and jokingly offered to be interviewed. When I explained that I was conducting a study on women inmates' sense of adulthood, one officer scoffed and replied with a sarcastic "Good luck!" 
The officer's attitude is not unique to this study; for instance, Waldram (2009, p. 4) described how security personnel mockingly told him "you'll hear nothing but bullshit." These comments reveal the lack of trust and, often, respect between gatekeepers and prisoners. Moreover, the attitude that gatekeepers hold toward the inmates also impacts how they view outside researchers and the questions they ask. In this study, many of the correctional officers made it clear in their informal conversations with me that they believed I was wasting my time by investigating women prisoners' subjective sense of adulthood.

Irrespective of the relationship among gatekeepers, researchers, and participants, access to prisoners depends very directly on approval and cooperation from formal and informal gatekeepers. Establishing a rapport with these gatekeepers is thus an absolutely necessary step in conducting prison research (Newman, 1958). As Feldman et al. (2003, p. vii) noted, gaining access requires learning "the art of self-presentation" and nurturing relationships in the field. This process, however, is marked by awkward and tense power differentials and is all the more stressful because the fate of the entire research project rests in the hands of the gatekeepers. Moreover, in prison research, gatekeepers are usually state actors who often have demands that conflict with the researcher's ethical and professional commitments. For example, prison researchers are frequently barred from guaranteeing participant confidentiality and anonymity (Reeves, 2010).

The importance of a critical assessment of the politics of access to prisons is further made evident in the context of prior researchers' conclusions regarding the significance of the political landscape in prison studies. Liebling (2001) described the implications of state actors' requests that certain questions be asked by penologists. She also discussed in detail the precarious nature of conducting prison research that might be critical of state institutions. Finally, she noted the difficulties researchers faced in compiling and disseminating politically-charged findings about topics such as prison conditions. While Liebling's discussion focused on prison research in the U.K., prison researchers in the U.S. also must consider the fact that different states' DOCs will vary in their openness to outside research in prison facilities. I thus build on Liebling's discussion by highlighting these state-level differences in review processes. This is significant because these state-to-state differences in openness to academic research suggest that, while researchers may be granted access to some facilities, there are whole prison populations that we are frequently prevented from studying. In the current era, gaining access to any prison to conduct research is a significant accomplishment (Bosworth et al., 2005). However, prison researchers must also acknowledge that what we know about prisoners in the U.S. may reflect gate-keeping decisions that are infrequently discussed in reports on qualitative prison studies.

As Reeves (2010) argued, discussions of access often focus exclusively on entering the research site. In the case of prison research, such a focus is necessary because prisons have historically been associated 
with a "fortress mentality" (Hart 1995, p.165) due to prison officials' reluctance to let outsiders in. Whether this reluctance stems from a suspicion of outsiders or from a basic interest in preserving prison security, access to prisons has become increasingly difficult in recent years (Bosworth et al., 2005). Rather than focusing exclusively on the difficulties of gaining access to a prison population, however, I highlight how access is an ever-changing element of prison research. I do this by describing how it was a continually negotiated process (Bondy, 2010; Reeves, 2010) each time I entered the prison in which the study was conducted. In so doing, I highlight one specific element of the politics of prison research: The ongoing role of gatekeepers throughout the research process.

\section{Methods}

The focus of this article is a study on women prisoners' constructions of adulthood while they are incarcerated. Specifically, I explored whether women prisoners conform to traditional markers of adulthood (especially marriage, employment, and parenthood) while they are incarcerated. Combining life-course literature on adult status markers and classic prisonization research, I also investigated whether these women believe that the prison environment and/or their status as prisoners altered their subjective sense of adulthood. Finally, I explored how women reconcile their status as adults with their status as inmates in a depersonalizing prison environment.

\section{The site}

As of 2011, women made up 5.4\% of the statewide prison population in Pennsylvania, and there are currently only two women's prisons in the state: SCI Muncy and SCI Cambridge Springs. After the long process of gaining access that is the focus of this article, I obtained both IRB and facility approval to conduct this study in SCI Muncy. Built in 1920 as a training school for imprisoned women between 16 and 30 years of age, SCI Muncy is now a women's prison in Muncy, Pennsylvania that also serves as the diagnostic and classification center for the state's female inmates.

As of December 31, 2013, there were 1,432 inmates housed at Muncy, and it was operating at $101.6 \%$ of its bed capacity of 1,410 inmates. (Bed capacity refers to the number of inmates that the facility can accommodate by filling all beds based on a number of logistical factors). In 2011, 56.8\% of inmates at Muncy were White (compared to $38.9 \%$ in the entire state), $34.8 \%$ were African-American (compared to $49.4 \%$ in the entire state), $6.6 \%$ were Hispanic (compared to $11 \%$ in the entire state), and $1.7 \%$ were classified as Other (compared to $0.7 \%$ in the entire state). $13.2 \%$ of the inmates were under 25 years of age, $50.2 \%$ were between 25 and 39 years of age, and 36.5\% were 40 years of age or older. Also in 2011, $3.1 \%$ of the inmates housed at Muncy were serving a life-without-parole sentence ( $n=152$ ), up $2 \%$ from 2010.

SCI Muncy is located two miles within Muncy, Pennsylvania, and the facility is surrounded by mountains and impeccably well-maintained grounds. The waiting room is located next to the front 
gate, and all visitors are required to show identification there, pass through a security check, and wait for an escort before being let out of the waiting room into the facility grounds. The most prominent building, located in the center of the grounds, is the main office/Superintendent's building. To the far right upon entering the gate is the yard, and the main office building is flanked on both sides by cottage-style cell-blocks where the inmates are housed. These housing units are labeled by letters and are organized in part by needs. For example, there is a specific housing unit for inmates with special needs. Overall, the facility grounds have the feel of a college campus. Indeed, many inmates spoke of the "campus" when referring to the facility grounds.

Given the exploratory nature of the project, I employed in-depth semi-structured interviewing as the initial data collection method. The interviews with inmates were conducted in a semi-private room in the prison and lasted between 32 minutes and 1 hour and 10 minutes. After using close-ended questions to obtain basic demographic information that could not be obtained from official prison records, the interview schedule consisted of mostly open-ended questions. These questions were aimed at understanding the women's perceptions of adulthood are, and the extent to which they believe these perceptions are affected by the prison environment. Table 1 contains demographic information on the final sample used in this study.

Table 1. Sample characteristics

\begin{tabular}{|c|c|c|c|c|c|c|c|c|c|c|c|}
\hline \multirow{2}{*}{$\begin{array}{l}\text { Senten } \\
\text { ce } \\
\text { length }\end{array}$} & \multicolumn{3}{|l|}{ Race } & \multicolumn{2}{|l|}{ Age } & \multicolumn{4}{|c|}{ Marital status } & \multicolumn{2}{|c|}{ Parental status } \\
\hline & W & B & $\mathrm{H}$ & $\begin{array}{l}\text { Younge } \\
r(<35)\end{array}$ & $\begin{array}{l}\text { Older } \\
(35-55)\end{array}$ & $\begin{array}{l}\text { Marrie } \\
\mathrm{d}\end{array}$ & $\begin{array}{l}\text { Divorce } \\
\mathrm{d}\end{array}$ & $\begin{array}{l}\text { Widow } \\
\text { ed }\end{array}$ & $\begin{array}{l}\text { Never } \\
\text { marrie } \\
\mathrm{d}\end{array}$ & $\begin{array}{l}\text { Childre } \\
\text { n }\end{array}$ & $\begin{array}{l}\text { No } \\
\text { childre } \\
\text { n }\end{array}$ \\
\hline $\begin{array}{l}\text { Recentl } \\
y \\
\text { Admitt } \\
\text { ed (6 } \\
\text { months } \\
\text { or } \\
\text { fewer) } \\
\text { ( } n=11)\end{array}$ & $8(72.7)$ & $2(18.2)$ & $1(9.1)$ & $6(54.5)$ & $5(45.5)$ & $2(18.2)$ & $5(45.5)$ & $0(0)$ & $4(36.4)$ & $7(63.7)$ & $4(36.4)$ \\
\hline
\end{tabular}




\begin{tabular}{|c|c|c|c|c|c|c|c|c|c|c|c|}
\hline $\begin{array}{l}\text { Short- } \\
\text { term (7 } \\
\text { months } \\
-2 \\
\text { years) } \\
(n=13)\end{array}$ & $3(23.1)$ & $6(46.2)$ & $4(30.8)$ & $6(46.2)$ & $7(53.8)$ & $2(15.4)$ & $5(38.5)$ & $1(7.7)$ & $5(38.5)$ & $\begin{array}{l}10 \\
(76.9)\end{array}$ & $3(23.1)$ \\
\hline $\begin{array}{l}\text { Long- } \\
\text { term ( } 5 \\
\text { years } \\
\text { or } \\
\text { more*) } \\
(n=11)\end{array}$ & $4(36.3)$ & $3(27.3)$ & $4(36.4)$ & $6(54.5)$ & $5(45.5)$ & $0(0)$ & $5(45.5)$ & $0(0)$ & $6(54.5)$ & $7(63.7)$ & $4(36.4)$ \\
\hline $\begin{array}{l}\text { Total } \\
(n=35)\end{array}$ & $\begin{array}{l}15 \\
(42.9)\end{array}$ & $11(31.4)$ & 9 (25.7) & $\begin{array}{l}18 \\
(51.4)\end{array}$ & $\begin{array}{l}17 \\
(48.6)\end{array}$ & $4(11.4)$ & $\begin{array}{l}15 \\
(42.9)\end{array}$ & $1(2.86)$ & $\begin{array}{l}15 \\
(42.9)\end{array}$ & $\begin{array}{l}24 \\
(68.6)\end{array}$ & $11(31.4)$ \\
\hline
\end{tabular}

Note: Percentages in parentheses. Abbreviations: W=White; $\mathrm{B}=\mathrm{Black}$; $\mathrm{H}=\mathrm{Hispanic}$ * Includes Hannah, a 20-year-old inmate who volunteered to participate because of her interest in Sociology even though I had not sent her a letter. Since she had served 3 years in Muncy (and 4 in total), and because her narrative reflected her self-identification as a longtermer, I placed her in the long-term category. She identified as a long-termer because she interacted primarily with other long-termers and lifers, she was serving a 6-12 year sentence length, and she had been facing a life-without-parole sentence.

Following the interviews, I sought and received IRB and facility approval once again, this time to continue communicating with a sub-sample of the women I had already interviewed. Based on preliminary analysis of the interview data using the grounded theory approach, $\underline{1}$ it was clear that the inmates' opinions on adulthood had their roots in events and experiences from earlier in their lives. Since I had, by necessity, capped the interview length at 1.5 hours, I decided that the study would benefit from supplementary, in-depth data on some of the participants' life-course patterns. For this reason, I engaged in mail correspondence with a sub-sample of the inmates. In a total of 38 letters with 11 inmates, I solicited details about key relationships, events, and transitions in the inmates' lives, beginning with their early childhood and ending with the period just before their current incarceration. $\underline{2}$

\section{Negotiating approval}

Institutional logistics such as the administrative processes and internal ethical requirements set by universities, state departments, and prisons are distinct from political dynamics such as efforts by gatekeepers to manage the research process and output. The tension between a university's IRB 
requirements and key principles of social science research have been discussed in detail elsewhere (Brainard, 2001; Gordon, 2003; Oakes, 2002). It should be mentioned, however, that the intrusion of the IRB in the research process that these scholars have noted was evident in this project. For instance, the IRB required that the informed consent form in this study be written at an eighth grade reading level. It also required, however, that the form include mandatory language determined by the institution. This language was not written at the eighth grade reading level, but the IRB stipulated that the language must be included regardless, despite its own reading level requirement. As the researcher, I was unable to assert much influence over the language of the informed consent form. In the context of qualitative prison research, where literacy levels are already a serious consideration when soliciting participants' consent, such constraints are especially problematic.

A further problem in the onset of the research lay in the fact that the IRB's approval was contingent on first obtaining approval from a prison facility. Yet approval from the first Department of Corrections to which I submitted my proposal was in turn contingent on IRB approval. After explaining the IRB requirements to a DOC representative, I was finally able to submit the proposal to the DOC before obtaining IRB approval from my institution. After two months of review, however, the DOC informed me that the project would not be approved. The reason they provided for the rejection was that it was not clear to the review committee what the benefit of the project would be to the Department of Corrections.

After requesting the opportunity to resubmit the proposal following a revision that made clear the practical, "real-world" benefits of the study, I was informed again, after another several months, that the project still could not be approved for the same reasons. I had highlighted in my revised proposal how the findings of the study might reveal important factors that contribute to women's reoffending/desistance motivations. I pointed out in particular that a study on women inmates' subjective sense of adulthood would advance the Department of Corrections' goal of producing information that can help provide for inmates' needs while in prison and thereafter.

Revising my proposal in these ways was helpful in clarifying my own sense of understanding of the contribution of the study; but at that stage, they were done keeping in mind neither my own preferences nor those of my prospective participants. Instead, they were driven by a concern with the preferences of the Department of Corrections. I admittedly did not have the DOC as the primary beneficiary of the research when I initially drafted the research proposal; rather, I hoped to explore a novel, intellectually interesting research question that could shed light on women prisoners' lived experiences and add to the literature on offenders' motives for desistance (Maruna, 2001; Massoglia \& Uggen, 2010). At the broadest level, I was driven by a strong interest in giving women prisoners voice at a time when interest in their lived experiences has not been the focus of sufficient recent 
penological research (Kruttschnitt \& Gartner, 2003). Yet to accomplish any of this, I first needed the approval of the Department of Corrections.

Even after clarifying how my research supported the DOC's goals, the review committee at the DOC was not convinced that the study was sufficiently beneficial "to the taxpayer." I was not comfortable changing the study's goals and questions to align more naturally with the DOC's interests, so I accepted the rejection and sought another research site. The reasons behind the rejection in this state are noteworthy for several reasons that highlight why, as Holland, Williams, and Forrester (2013) argued, ethical decision-making must be viewed relationally. These scholars highlight the role of participants in ethical decision-making. The reasons for my rejection, however, emphasize why scholars conducting prison research must also confront a plethora of ethical questions that are triggered by the role of the organizational gatekeepers. The primary question the rejection prompted was: Who is this research intended to benefit? To use Becker's (1967) terms: Whose side are we on?

Even for researchers striving to remain neutral when conducting prison research (however difficult it is to attain this goal), when conducting research in correctional institutions, "the researcher must be prepared to make the case to prison management of the potential benefit of their research to correctional organizations" (Hart, 1995, p. 167). Scholars in the U.K., for instance, noted the need for prison researchers to be aware of the political benefits and drawbacks of proposed studies (King \& Liebling, 2007; Liebling, 2001) as well as the extent to which Home Office funding can apply pressure to conduct a study in a specific manner (Liebling, 1999). The study is thus affected by political considerations that are far-reaching in their implications for what kind of penological knowledge is produced and how.

My rejection experience also reinforces the political nature of prison research by highlighting the extent to which such research is contingent on being well connected in the field. For example, I was at one point told that having a contact pushing for me from inside one of the facilities would have been helpful in obtaining approval. The fact that researchers can benefit from having insider experiences/contacts at research sites is well known (King \& Liebling, 2007; Schlosser, 2008). However, this feature of conducting prison research is particularly vexing for novice researchers who have yet to establish themselves, both in their fields and among research review committees in state Departments of Corrections (Schlosser, 2008). As Liebling (2001, p. 481) pointed out, conducting prison research requires "some thought given in advance to ethics (for example, fairness) and politics." Fledgling prison researchers with limited contacts in the field should consider in advance how far they are willing to change the goals of their research to meet the demands of state actors. The age-old question of 'whose side am I on?' becomes all the more important when the fate of the entire project hinges on the researcher's response. 
The challenge of how far researchers should permit gatekeepers to manage the research process - and the research questions especially - reinforces how organization approval dictates what penologists know about women prisoners. Although Hart's (1995) advice that researchers be prepared to outline the benefits of their research to the correctional organizations is onpoint, it is imperative that we confront the implications of such advice for what we know about inmate populations. Qualitative research on inmates and prison culture has already been stunted by the daunting administrative difficulties involved in negotiating approval (Bosworth et al., 2005). Additionally, even those projects that have been approved may reflect the interests of state agencies and institutions, since commencement of any prison study is contingent on cooperation from these organizational bodies. Among penologists, therefore, only a handful are conducting qualitative prison research; and, in such research, there is little opportunity to pursue questions that state institutional actors cannot justify approving based on an assessment of the project's contribution to organizational agendas.

As Cook and Fonow (1986, p. 11) argued, research on women should critically analyze the influence of gate-keeping on topic selection and research funding." Topic selection in particular is likely to be affected a great deal by the administrative and political difficulties involved in conducting prison research in current-day U.S. For this reason, the voices we give to prisoners may be partial and fragmented as a result of which questions we are permitted to pursue. Qualitative penologists must both acknowledge and seek to address these issues when examining the political nature of prison research in the U.S., even if there is no clear-cut way to resolve them.

After my initial rejection, approval from the Pennsylvania DOC came easily. The director of research at the DOC, the head of the research and review committee, and the Superintendent's Assistant at SCI Muncy were all supportive and encouraging of the project in its original form. I was fortunate in this instance to have the opportunity to discuss my project with the head of the research committee in the Department of Corrections (and was able to state as such when I submitted the proposal). I later encountered the same difficulties that Schlosser (2008) outlined in her description of the administrative obstacles involved in conducting prison research. However, the fact that the gatekeepers in Pennsylvania were supportive of the project meant that approval came fairly quickly.

The state-to-state differences in how cooperative formal gatekeepers were further highlights how our knowledge of inmate populations may be far more reflective of political considerations involved in gaining access to prisons than qualitative penologists in the U.S. have thus far acknowledged. In particular, qualitative researchers should seek to determine whether state-to-state differences in officials' openness to external research reflect differences in prison conditions, security considerations, or political motivations. Doing so will, at the very least, permit a recognition of why and how our knowledge about prisoners is limited by our inability to access inmates whose lived experiences might differ radically from those of the inmates to whom we do have access. 
To conclude, there is no doubt that qualitative researchers are generally circumspect in discussing how their findings may have been affected by dynamics in the field. However, the methodological and epistemological issues that stem from being denied access to whole prison populations (while being granted access to others) have not been tackled in either the penological or the qualitative methodology literature. In addition to the administrative difficulties that have been well documented in the prison research (Schlosser, 2008), qualitative criminologists should recognize that issues of gate keeping raise important epistemological questions about the state of prison research in general.

Placing criminological and penological knowledge within the political, social, and structural context that it is created in is particularly important for researchers approaching prison research from, for example, a feminist standpoint aimed at empowering women prisoners through research. This is because researchers hoping to give voice to incarcerated women may not have access to many of these women because of gatekeepers. Such researchers should make strong efforts to reach inmate populations in states that may be reluctant to grant researchers access to prison facilities. However, they must also be aware of the fact that prison officials may be reasonably reluctant to permit researchers to enter prison facilities with an explicitly political agenda. Since prison officials are assigned the primary task of containing and controlling inmates, researchers should understand that their political goal of empowering inmates may be at odds with the responsibilities of prison officials who block access to prisons.

Further, prison officials may view studies with obviously political agendas less as social scientific research and more as advocacy that conflicts with their organizational responsibilities. The gatekeepers may believe, as Newman (1958, p. 127) noted, that "the most valid research can be conducted by a trained outsider who has no axe to grind on any aspect of correctional structure." Given this, well-established researchers are perhaps in the best position to conduct research that has explicitly political roots and/or implication. These researchers are more likely than novice prison researchers to have earned the status and legitimacy that comes with experience in the field. Moreover, veteran researchers are more likely than fledgling ones to have earned the trust of prison officials by demonstrating responsibility and transparency in the research process. Novice qualitative researchers, on the other hand, would benefit from becoming involved in prison programs that grant them legitimacy and permit them to establish a comfortable rapport with inmates and staff.

Even if the issues of access are surmounted, however, researchers who hope to empower women inmates through their research may find it problematic that gatekeepers require a clear vision of how the study will benefit the state. As Newman (1958, p. 128) pointed out, "much prison research is, or can be, basic and theoretical" and penology does not have as its sole goal the creation of practical knowledge. Prison researchers should nevertheless be prepared to explain, as I was forced to, how the study will benefit the taxpayer. For scholars who wish for their work to benefit the prisoners rather 
than the state or the abstract taxpayer, such a request can lead to intellectual and ethical dilemmas for which researchers should be prepared.

Prison researchers' sympathies often lie with their participants (Liebling, 2001). Indeed, a researcher's ability to empathize with, relate to, and become involved with participants is a key part of the research process. Researchers' sympathetic feelings toward inmates could, however, conflict strongly with state actors' questions about how proposed research findings could benefit the state instead of the inmates. Yet if we are to continue to conduct prison research at all, working with-rather than against-state actors is necessary (Newman, 1958). How far prison researchers are willing to accede to the demands of state institutions is a personal choice, but it is one that should be duly addressed in an open manner in research reports.

\section{Access: A continually negotiated process}

Qualitative researchers have argued that obtaining IRB approval must not be considered the main ethical event in the research process (Holland et al., 2013), and that more attention should be paid to ethics in practice (Gabb, 2010). Holland et al. (2013, p.2), for example, emphasized that ethical decision-making is "worked out in the field." The relational nature of ethical decision-making during rather than before the research process is no doubt an important issue, and one I turn to in this section. Specifically, I outline how access in my prison research proved to be a continuous process of negotiation primarily in two ways: 1 . in terms of actual access into the prison facility; and 2. in terms of access to participants.

As prior research has noted, access in qualitative research is a process of constant negotiation (Bondy, 2010; Reeves, 2010), and access to prisons may be especially tenuous because prisons, whether in the U.S. or elsewhere, are volatile institutions subject to frequent local tensions (King \& Liebling, 2007). In the case of the current study, gaining continued access to participants for the study proved to be almost as difficult as gaining initial entry into the prison. In addition to the numerous difficulties I faced in gaining initial access to the prison, it was clear that access to the facility for each specific visit could be revoked by gatekeepers at any point because of day-to-day events at the prison.

My goal was to conduct interviews on a weekly basis over a span of approximately four months. However, it soon became apparent that permission to enter the facility could be denied at any point, despite the full cooperation of the Superintendent's Assistant. For example, I received notice on the morning of one of the scheduled interview days (half an hour before departure to the prison) that the facility was in lock-down mode, and all the interviews for that day had to be cancelled. Two weeks later, the Superintendent's Assistant informed me that all interviews for the ensuing two weeks had to be cancelled, despite already scheduling the interviews and confirming the schedule two days earlier. 
On occasion, moreover, even after arriving at the facility, I was required to sit in the waiting room for almost an hour until someone was made available to escort me from the gate to the building where I was conducting the interviews. At other times, I was asked to wait because my name was not on the list of approved visitors that the correctional officers used to grant access to the facility grounds. The correctional officers who serve as gatekeepers in prison research quite literally guard gates. These gatekeepers have the authority to deny access to the prison site "at any moment, and for any reason that does not have to be disclosed" (Waldram, 2009: 4).

Fortunately, there was no occasion when I arrived at the prison and was turned away. However, the perpetual delays upon my arrival meant that when I was finally able to begin interviews, it was often time for the inmate count, a half-hour period during which inmates were not permitted to move around the facility. Cumulatively, these delays meant that I was almost never able to do as many interviews as I intended to on any given visit. The unpredictability of field research is thus exacerbated in prison settings in a way that makes conducting prison research an overwhelming task. The flexible model of qualitative research, which is designed to accommodate a high degree of unpredictability during fieldwork, was especially useful in this study. It must be emphasized, however, that researchers studying prisoners or prisoners should refrain from making concrete plans and timelines to which they most likely cannot adhere.

In this study, the role of the Superintendent's Assistant as gatekeeper strongly shaped how the research process unfolded. It is not necessary that prison researchers have adversarial relationships with correctional officials (Liebling, 2001), and in this study the Superintendent's Assistant at SCI Muncy was in fact wholly supportive of the research. Despite this, however, his role as gatekeeper to the facility became apparent at several points during the research process. Although his gate-keeping responsibilities interfered with the research process, our relationship was not adversarial, nor was I unsympathetic to the difficulties he faced in juggling multiple responsibilities related to management of the facility. My experience suggests that prison researchers should not view gatekeepers as mere obstacles in their research. Rather, as Liebling (2001, p. 476) suggested, they should attempt to understand "the constraints under which the so-called powerful operate." In addition to establishing a more cooperative working relationship with gatekeepers, remaining open to the views and preferences of gatekeepers can also yield a much more well-rounded understanding of the prison environment generally. While our primary interest may be in studying prisoners, therefore, making an effort to understand the views of gatekeepers can be invaluable.

Prison researchers must also be prepared for constantly shifting and fluid power dynamics. While researchers are often at the mercy of prison officials (Schlosser, 2008), inmates often view researchers as outsiders who are acting from a position of power/authority. For example, one participant asked me at the end of her interview if I could help her with her plans for buying a building so that she could run 
a daycare for low-income mothers. Another inmate asked me in a letter whether I could assist her in her goals to write a book and open a business. In addition to the inmate-outsider distinction, there are also social class issues that play a role in how inmates perceive researchers. When inmates asked for my help in opening a daycare or writing a book, they presumed I enjoyed a certain level of privilege that I could draw on to assist them. Although the women in this study did not attempt to gain access through me to restricted or unavailable goods and services, outsiders who enter prisons as experts are often presumed (by inmates and sometimes staff members) to be potentially helpful to inmates. Researchers entering prison should thus be especially conscious of how inmates may perceive their race, age, gender, and social class, all of which can affect inmates' motivations to participate in a study.

It would be simplistic, however, to view the researcher's position as shifting from powerless to powerful as he/she moves from interacting with officials to interacting with inmates. The researcher is no doubt in a position of power in some ways when interacting with inmates. Most obviously, he/she does not carry the label of inmate and has the basic freedom to return to the outside world after the interview is completed. However, there are key ways in which inmates maintain a position of power in the researcher-researched relationship. In the current study, there were weeks when I would visit the prison only to be told that inmates did not wish to participate any longer, despite their initial interest in the project. Inmates scheduled to participate in the study would report feeling unwell or simply being uninterested in continuing their participation in the project.

Fortunately, only one inmate in this study backed out entirely after agreeing to participate, and this was because the interviews were running behind schedule, and she had been waiting for an hour before she left. However, it is important to recognize that inmates are likely to discuss the study with one another. As a result, some may drop out once they learn from other inmates that they will not benefit from participation, while others may lose inter est after learning further details about the study. Prison researchers can do little more than accept the inmates' unwillingness to participate, which underscores the extent to which access cannot be considered complete when a researcher has been granted entry into prison grounds.

Similarly, although gatekeepers are supposedly the power-wielders in prisons, outside researchers threaten prison order by their mere presence in an extremely regimented and routinized environment. Further, they have the ability to publicize flaws in the facility and its treatment of inmates (Liebling, 2001). Even those researchers not pursuing an explicitly political research question should thus be aware of the political implications of their presence in prison facilities. Showing facility officials and other gatekeepers the same consideration, warmth, and respect that researchers show their participants (Liebling, 2001) would likely go a long way in establishing the trust and cooperation of gatekeepers. 


\section{Prison research by mail}

Bosworth et al. (2005) have elsewhere described in detail the research that they conducted through mail with prisoners in the U.S. The authors noted that "doing research by mail offers a new approach for criminologists and others dealing with what are routinely referred to as problem populations"” (Bosworth et al. 2005, p. 251). In the Bosworth et al. (2005) study, each participant became involved in the study by responding to an advertisement posted in a prison newsletter, and the researchers thereafter communicated with the prisoners exclusively by mail. Building on the informative discussion of prison research by mail of Bosworth et al. (2005), I focus here on how mail correspondence can be used to supplement interview data.

Perhaps the most salient benefit of corresponding with inmates by mail is that the researcher has the opportunity to gather more in-depth qualitative data without having to repeatedly negotiate physical access to the prison facility previously described. Instead, the researcher can conduct simultaneous data collection and analysis consistent with the tenets of the grounded theory approach. Specifically, following initial data collection and preliminary analysis of interview data, the researcher can correspond with inmates by mail to fill in gaps in the data or to collect further data until categories are appropriately saturated. Instead of physically returning to the field, therefore, researchers can instead collect data from a distance. This is especially useful because access to the prison facility in any single visit is never guaranteed even once approval has been obtained for the project as whole.

That researchers can conduct primary data collection in prisons from afar through letters should not be taken to mean that gate-keeping issues are no longer relevant. To the contrary, the presence of gatekeepers is in some ways even more salient when conducting prison research by mail. Most importantly, because prison officials are highly likely to monitor incoming and outgoing inmate mail, inmates who are wary of officials reading their letters may be reluctant to participate. Although it is impossible for a researcher to guarantee the confidentiality of the information that inmates share in letters, researchers should leave the decision to participate in the hands of the inmates themselves. In this study, I stipulated in the informed consent form and recruitment letter used in the mailing portion that inmates' mail would be handled according to normal PADOC policies. Inmates were more than willing to write letters to me, despite this fact, and some offered me even more detail than they did in the interviews.

There are a number of further drawbacks of conducting prison research by mail that researchers should note. Perhaps the most significant obstacle to this kind of research is that prisoners' literacy levels might exclude certain inmates from participation in prison research by mail. IRBs typically require that informed consent forms are written in simple and non-technical English. As mentioned, the informed consent form in this study was written in eighth grade-level English. However, there may be some inmates who can understand English at this level, but who would have trouble articulating 
their thoughts in writing even at this level. Researchers should be aware that these inmates will most likely simply not respond to invitations to participate in mail correspondence.

It should be noted, however, that inmates look forward to receiving mail as a means of maintaining ties with the outside world. The majority of inmates whom I interviewed in this study, for example, described the value they placed in writing to and receiving letters from their family members outside prison. Using mail correspondence with inmates to supplement interview or ethnographic data encourages inmates who would otherwise be reluctant to write letters to a stranger. While it is impossible to state conclusively why inmates chose to participate in the mailing portion of this study, the rapport I established with the inmates before inviting them to write letters appeared to help a great deal.

At least one inmate in this study had obvious language-related difficulties in articulating her thoughts in writing, and her letters were somewhat challenging to understand because of linguistic issues. Nevertheless, she was very enthusiastic about participating in the mailing segment of the study, and she was especially excited about continuing her interaction with me beyond the interview. Even those inmates who have low literacy levels may thus attempt to surmount their discomfort with writing if they wish to engage in mail correspondence with a researcher. Encouraging participation by establishing a friendly rapport with inmates before inviting them to write letters is one way that researchers can overcome difficulties associated with some inmates' low literacy levels.

Another reason mail correspondence may be best suited to supplementing rather than replacing other data collection methods is that meeting the inmates before inviting them to write letters permits a loose and informal assessment of the inmates' literacy levels. In this study, participants were required to sign an informed consent form before the interview began. Before they signed the form, I asked the participants whether they had any questions or concerns about the research process generally or the information on the form specifically. There was no participant in this study who expressed discomfort or confusion with the language used in the informed consent form. It is possible, however, that the inmates were reluctant to voice their difficulties in understanding the informed consent form. They may have refrained from voicing their discomfort to avoid embarrassment or even to preserve their relationship with an outsider and/or to protect their participation in the project. Although there is no evidence that this was the case, prison researchers should recognize that consent in prison studies may be less freely given than in studies conducted in more unconstrained settings.

Despite the possibility that some inmates may have difficulties because of their reading or writing level, it is my view that researchers should not shy away from conducting prison research by mail without first meeting with participants and gaining a sense of their comfort with reading and writing. This is a major reason why mail research is best suited to supplementing data obtained through ethnographic or interview methods - meeting with participants and establishing a rapport with them 
before asking for their participation via mail is crucial. This is especially important because participants may feel particularly uncomfortable with the notion of participating in research conducted by total strangers. In this project, meeting the inmates for an interview not only established the parameters of the research project; it also gave participants a chance to ask questions and/or seek clarification about the project face-to-face.

Finally, using mail correspondence to supplement rather than replace interview or ethnographic data is important because many inmates may agree to participate in the mail correspondence but stop writing letters before that portion of the study is complete. Prison life is very stressful, and despite its monotony, it can also be very chaotic. Further, inmates face a number of challenges of which researchers are simply unaware unless the inmates disclose them. These challenges can result in prolonged delays (and sometimes even an abrupt termination) in mail correspondence that can interfere with researchers' projected timelines for the completion of prison studies. After a long period of silence, Marie, for example, notified me that her father, who was suffering from bone cancer, had passed away. In her previous letter to me, Marie had explained that her father had only a few months left to live. The tumult resulting from her father's illness and subsequent passing had understandably resulted in delays in Marie's correspondence with me.

I hope this finds you well. Once again, I apologize for the delay. My dad passed July 9th. I usually call home every evening. For some reason that day I got a morning phone time. When I talked to my dad I had no idea he would be gone in a few hours. I miss him terribly; I am happy that he is at peace, but I'm lost without him. (Marie, 31 years old, serving a life-without-parole sentence for first-degree murder)

The extract above demonstrates not only the challenges that some inmates face when serving their sentence; it also reveals the extent to which inmates use their letters to communicate thoughts and emotions that are not directly relevant to the study's goals. These deeply personal, first-hand accounts, however, were crucial in providing a fuller picture of the experiences and relationships that shaped the inmates' opinions on adulthood and adult roles. Although these narratives were invaluable in this study, researchers should still be prepared for significant, often unpredictable, and unexpected delays when conducting prison research by mail. For this reason, it is good practice for researchers to seek alternative data collection methods to answer key questions and thereafter use letters to supplement, deepen, and enrich the data.

For qualitative prison researchers working from a perspective geared toward empowering participants, mail correspondence with inmates can be especially appealing. In several interviews, the women I spoke with mentioned that receiving mail was something they looked forward to. For them, receiving letters was one major way of breaking the monotony of prison life and maintaining ties with the outside world. Marie even said that she expected inmates to be enthusiastic about participating in 
the interview segment of the study simply because receiving the recruitment letter was rewarding. Continued contact with participants after conducting interviews can thus be gratifying for inmates. This is both because it lends itself to added contact with the outside world, and because participants may feel that the significance of their contribution goes beyond simply a one-hour interview.

Sheila, for example, repeatedly expressed her gratitude for being able to participate in the mailing segment of the study and even asked to continue her participation in this segment once she was released to a halfway house. Unfortunately, I had obtained IRB approval only to conduct the research at SCI Muncy, and I was therefore unable to continue Sheila's participation once she was released:-

I was very happy to get your letter. I am very grateful that you still want me to be in your research. I will help you, [Miss Janani] in any way I can and I hope I will be able to help with any questions you ask me. I have nothing to hide. If this could help anybody, I would be so grateful. (Sheila, 45 years old, serving 8.25-20 years for aggravated assault)

As Bosworth et al. (2005) noted, mailing with inmates often involves a certain degree of back-andforth conversation. This gives participants the freedom to voice opinions and thoughts that go beyond the specific questions related to the study. In an interview, participants may feel compelled to confine themselves to succinct, targeted answers to interview questions. Responding to a letter, on the other hand, permits inmates to collect their thoughts at leisure and discuss the issues that they believe are the most relevant and helpful. Although this can result in researchers receiving excess information that is not helpful for the precise purposes of the study, this method of data collection is consistent with the view (held by many qualitative researchers) that we ought not to impose restrictions on the data we collect because of our own preconceived notions of what is or is not important (Glaser, 1972).

Researchers should also be aware, however, that inmates may discuss their thoughts with one another before penning them down in letters. The data researchers receive from inmates in the form of letters may thus reflect not only the participants' views, but also the collective input of multiple inmates and perhaps even prison staff members. For this reason, placing the content of the inmates' letters in the context of the interview data - through a process of triangulation, perhaps - is helpful in gaining a well-rounded understanding of the inmates' views in totality. Moreover, asking focused, personal questions that elicit first-hand, personal narratives from the inmates about their own life experiences is important. For example, in the letters I sent to inmates, I asked inmates about their families, their childhood memories, their relationship histories, and so on, rather than their general views on adulthood and adult roles.

Many scholars have critically analyzed the relationship between the researcher and the researched. In discussions of reflexivity in the research process, they have argued that this relationship should not be marked by power differentials and clear-cut boundaries between the researcher and the participant 
(Ellis \& Berger, 2002; Holstein \& Gubrium, 1995). Developing a relationship with a participant that is not marked by issues of power and authority is no doubt a worthwhile task in an interview. This, however, is a particularly difficult task in a prison setting. The interviews in this study, for example, were conducted in a conference room and were sometimes interrupted by correctional officers and other prison officials who needed to speak with me. Participants were always led to and from the interview room by a correctional officer, and some had to wait on a bench outside the interview room until they could be accompanied into the room before the interview or out of the building following the interview. Even though the interviews themselves were always private, conducting interviews in a prison environment made it difficult to ignore the differences between my own status as an outsider in the prison facility and the participants' status as inmates. $\underline{4}$

Because inmates can write letters at their own pace and in a setting where they feel most comfortable, mailing with inmates can give them more control of the research process. One inmate mentioned that there had been a delay in responding to my letter because the block she lived in had been condemned, and moving had been chaotic; she noted in her eight page, single-spaced letter that since things were now more settled, she would be able to answer my questions "in peace." Giving inmates the time to reflect on their thoughts before responding to questions equalizes what can otherwise be a stark power differential. In this study, it also yielded very deep and intimate data that inmates took the time to record on paper. The extracts below demonstrate the level of detail that the inmates provided in their letters about their familial relationships:

My dad would drink, come home from work, and if his dinner wasn't heated up, he would throw the pots on the floor with food flying everywhere. My mother and father would celebrate holidays [and] birthdays. My sister and I never went without. When my mother had enough with him, we waited until he was sleeping one day. I was 14 years old and can't never shake out the memory when we left. She was yelling at us to carry our stuff. He didn't find us for awhile. (Camila, 34 years old, serving 3-10 years for robbery)

Another woman shared thoughts about her childhood:

My older brother and sister lived at home for some of my childhood. They both spoiled me. They both worked, so [they] would come home with toys for me on payday. My brother taught me to swim. He would take me to visit his girlfriend, now-wife, at college. He played softball and took me to his games. My sister would take me to the park, movies, and even let me hang out on dates with her now-husband. He would run to get me ice cream from the ice cream truck every time he came over. Even when my brother and sister moved, married, and had children, I slept over at their houses often. (Marie, 31 years old, serving a life-without-parole sentence for first degree murder) 
Researchers may find relinquishing control of the process somewhat uncomfortable. However, using mail correspondence to supplement rather than replace interview or ethnographic data permits researchers to control significant portions of the research in the interview setting. At the same time, it transfers some of this control to participants at a later stage in the research process, which allows them to then decide if and how they wish to respond to the letters in a setting that is far less structured than the interview. The result is that many inmates use the extra time and space to formulate thoughts that they might not otherwise share. Whether this is because it can be hard to share these with a stranger face-to-face or because it takes time that is unavailable in an interview to articulate such thoughts, the level of depth in the inmates letters was crucial to the study.

Barbara, for instance, even went as far as offering to share her own personal writing with me. As a means of coping with her incarceration, she had penned down some of her thoughts during the early phases of her incarceration. The extract below from her writing exemplifies the richness of the lifehistory data in the inmates' letters:

I would like to say that my change started when I came to prison in 2004 , but the truth of the matter is that I lived a normal everyday life experimenting with weed, acid, and liquor at the age of 15 up until I was 17 and had my first child. My son, Benjamin. $\underline{5}$ Everything seemed to be going good for me. I was filled with joy! I lived with my sister Leona. She was like a second mother to me - my best friend and my everything. Then when she died in ' 92 , I felt as though a big part of me had died with her. That's when I started to change, but all in the wrong ways. My life started to spiral out of control. (Barbara, 40 years old, serving 10-20 years for kidnapping to inflict injury)

In her article on conducting research in an English prison, Liebling (1999) described in detail the frustration of a prisoner who wanted to use the research interview to talk free flow and who found the structured format of the interview frustrating. For such participants experiencing intense frustration, writing letters can be cathartic. The excerpt from the first letter Barbara wrote to me in response to my questions about her childhood reveals the general attitude that some participants took toward the mailing portion of the study:

You know, I would also like to thank you for giving me this opportunity to be a part of your research, for not only will I be helping you out, but you will be helping me out in the process as well. I take this like some kind of therapy to be able to dig deep inside of myself and be able to talk about some of the things that perhaps some of my closest family members don't even know about me. So again, thank you so much. (Barbara, 40 years old, serving 10-20 years for kidnapping to inflict injury)

The collection of data through both interviews and mail correspondence also stands to have the benefits that come with many mixed-methods research designs. In this study, the integration of the 
two methods occurred at the analytic stage. Specifically, I employed a process of triangulation so that the narratives from the inmates' letters supplemented, deepened, and saturated interview data (Moran-Ellis et al., 2006). As such, collecting data using different methods was used to "generate an overarching account of the phenomenon," (Moran-Ellis et al., 2006, p. 56) where inmates' narratives from letters were used to fill gaps and enrich their more limited, targeted interview responses. While the inmates' self-written narratives were used to supplement interview data, they were not considered less significant data in the project. Instead, they served the purpose of obtaining deeper, thicker data designed to answer the same research questions as the interview data.

I also used the letters as an opportunity to gain participants' perspectives on some of the conclusions I was drawing from their interview data. This gave participants the opportunity to respond to my analytic thoughts, which is something that many scholars describe as a key component of qualitative research (Bloor, 2001; Tracy, 2010). As Tracy (2010, p. 844) noted, researchers "do have control in providing the space and opportunities for member reflections, and in doing so, provide opportunities for additional data and elaboration that will enhance the credibility of the emerging analysis." The letters thus served the important purpose of continuing my interaction with the participants in order to refine and revise analytic thoughts as the project unfolded. In her interview, Kayla said the following about her relationship with her parents:

I just, um ... all my sisters were adopted, and I just never thought that, um, somebody else could take the place of my mom and dad. Yeah, I was mad at my mom and dad for what they did to me, but I felt like nobody could be my mom or my dad. My mom and my dad were my mom and my dad. I just ... I didn't feel comfortable with calling somebody else Mom and Dad.

In a letter to me, however, when I asked her to describe her relationship with her parents in the context of those comments, Kayla wrote:

I met my mother at 15 years of age and that did not go good or as planned at all. That lady is sick in the head. I'm very angry at the people that had me. In my eyes, they are not parents; they were donors to make me! I have met many people-friends or friends' parents that have taken me in and call me their daughter or I call them my parents because they have played that role in some way. (Kayla, 18 years old, serving 2.5-5 years for aggravated assault)

This apparent contradiction in her views resulted in an extended conversation through letters about her relationship with her parents that both clarified and deepened the analytic conclusions I drew from Kayla's narrative. The letters thus presented an important opportunity not only to obtain new, additional data, but also to solicit feedback and clarification from the participants about my interpretation of their stories. 


\section{Conclusion}

In this article, I applied a definition of reflexivity that emphasizes the "dissecting [of] the social conditions and techniques of production of the scientific project" (Wacquant 2011, p. 441). Drawing on this definition, I argue that prison researchers must be aware of how the politics of gate keeping and access to prisons affects what we know about inmate populations. Access to prison facilities has become increasingly complicated from an administrative standpoint (Bosworth et al., 2005). It is important to note, however, that in addition to the administrative difficulties involved with conducting prison research, there are very real concerns about whose voices we hear when prison studies are approved. My experience with seeking approval in different states in the U.S. highlights the extent to which gate keepers can influence which inmates researchers can have access to, and which questions we can ask those inmates.

Prison researchers should be aware that the state of knowledge about the lived experiences of inmates and prison culture may be affected by the decisions of gatekeepers. To the extent that state actors deny researchers access to prisons because studies conflict with the officials' goals to contain and control prisoners, researchers must understand and respect the limitations on what can be studied in prisons. In such cases, prison officials and other state actors should not be viewed as problems to be overcome at whatever cost. However, studies are also rejected because they do not advance state DOC agendas, such as when it is unclear how a study will benefit the taxpayer. In these instances, qualitative prison researchers must acknowledge that what we know about prison conditions and inmates' lived experiences may be shaped by organizational agendas that are rarely explicitly acknowledged in research reports. Prison researchers should thus make significant efforts first to understand how to confront questions about who the beneficiaries of prison research ought to be. Further, there should be discussions about how the answers to this initial question affect the body of knowledge on prisons and prisoners. Finally, prison researchers should make every effort to explicitly acknowledge and assess the ways in which meeting DOC standards for research shaped the questions they asked and the research process generally.

Considering the very real difficulties involved in gaining access to prison populations, prison researchers should seek and develop alternative methods of studying prisoners. Corresponding with prisoners by mail is one fruitful method of collecting data from prisoners without having to undergo the arduous task of gaining and then maintaining physical access to the prison facility itself. There are several serious shortcomings to collecting data this way; however, I argue that using mail from inmates to supplement rather than replace interview or ethnographic data resolves some of the major drawbacks to this form of data collection. For example, researchers can use interviews to obtain more structured, targeted data while relying on the letters from inmates to deepen and enrich themes that emerge from the interviews. Moreover, by giving inmates some control over the research process, the power differential that is accentuated in interviews conducted in the prison environment is lessened to 
some degree. Finally, as an inmate in this study noted, writing letters about their lives can be therapeutic for some inmates.

Conducting prison research from afar does not overcome all the gatekeeping issues inherent in any prison study. However, my experience suggests that after establishing an initial rapport with gatekeepers and inmates and collecting data in-person at the facility, both parties are willing to cooperate with data collection efforts made from afar through mail correspondence. Gatekeepers play a role in shaping the research process by, for example, insisting that inmate mail cannot be kept confidential. However, having a trusting and transparent relationship with both gatekeepers and inmates permits the researcher to gain supplementary, in-depth data that are difficult to obtain in the prison environment itself.

Moreover, extending access to inmates by corresponding with them by mail presents an opportunity to seek participants' views on analytic thoughts. Writing letters with inmates also permits an exploration of changes in participants' views over time. The latter is a feature that is especially helpful when studying prisoners, whose responses to incarceration are strongly affected by the amount of time they spend in prison (Clemmer, 1940; Kruttschnitt, Gartner, \& Miller, 2000). In sum, prison researchers should seek creative ways to study prison populations while respecting and working within the relevant administrative parameters. At the same time, however, they should endeavor to include in their research reports a critical assessment of how these parameters shaped their research questions, data collection methods, and the overall research process.

\section{References}

Altheide, D. L. \& Johnson, J. M. (1994). Criteria for assessing interpretive validity in qualitative research. Denzin, N. and Lincoln, Y.S. (Eds.) Handbook of qualitative research. Thousand Oaks, CA: Sage Publications.

Bloor, M. (2001). Techniques of validation in qualitative research: A critical commentary. In Emerson RM (Ed.), Contemporary field research. Prospect Heights, IL: Waveland Press.

Bondy, C. (2012). How did I get here? The social process of accessing field sites. Qualitative Research, published online before print April 26th, 2012.

Bosworth, M., Campbell, D., Demby, B., Ferranti, S. M., \& Santos, M. (2005). Doing prison research: Views from inside. Qualitative Inquiry, 11, 249-264.

Brainard, J. (2001). The wrong rules for social science? The Chronicle of Higher Education March 9.

Broadhead, R. S. \& Rist, R. C. (1976). Gatekeepers and the social control of social research. Social Problems, 23, 325-336. 
Charmaz, K. (2003). Qualitative interviewing and grounded theory analysis. Holstein J. A. and Gubrium J. F. (Eds.) Inside Interviewing: New Lenses, New Concerns. Thousand Oaks, CA: Sage Publications.

Christians, C. G. (2005). Ethics and politics of qualitative research. Denzin,

Clemmer, D. (1940). The prison community. New York, NY: Christopher Publishing House.

Cook, J. A. and Fonow, M. M. (1986). Knowledge and women's interest: Issues of epistemology and methodology in feminist sociological research. Sociological Inquiry, 56, 2-29.

Denzin, N. K. and Lincoln, Y. S. (Eds.) The SAGE handbook of qualitative research, 3rd Edition. London, England: Sage Publications.

Duke, K. (2002). Getting beyond the 'official line': Reflections on dilemmas of access, knowledge and power in researching policy networks. Journal of Social Policy, 31, 39-59.

Ellingson, L. L. (1998). 'Then you know how I feel': Empathy, identification and reflexivity in field work. Qualitative Inquiry, 4, 492-514.

Ellis, C. \& Berger, L. (2002). Their story/my story/our story: Including the researcher's experience in interview research. Gubrium, J.F. and Holstein, J.A. (Eds.). Handbook of Interview Research: Context and Method. Thousand Oaks, CA: Sage.

Emmel, N., Hughes, K., Greenhalgh, J., \& Sales, A. (2007). Accessing social excluded people-Trust and the gatekeeper in the researcher-participant relationship. Sociological Research Online, 12.

Feldman, M. S., Belle, J., \& Berger, M. T. (2003). Gaining access: A practical and theoretical guide for qualitative researchers. New York, NY: AltaMira Press.

Gabb, J. (2002). Home truths: Ethical issues in family research. Qualitative Research, 10, 461-478.

Giallombardo, R. (1966). Society of women: A study of a women's prison. New York, NY: John Wiley and Sons.

Glaser, B. (1992). Basics of grounded theory analysis: Emergence vs. forcing. New York, NY: Sociology Press.

Goodwin, J. \& Horowitz, R. (2002). Introduction: The methodological strengths and dilemmas of qualitative sociology. Qualitative Sociology, 25, 33-47.

Gordon, E. J. (2003). Trials and tribulations of navigating IRBs: Anthropological and biomedical perspectives of "risk" in conducting human subjects research. Anthropological Quarterly, 76, 299-320. 
Hart, C. B. (1995). A primer in prison research. Journal of Contemporary Criminal Justice, 11, 165-176.

Heffernan, E. (1972). Making it in prison: The square, the cool, and the life. New York, NY: John Wiley and Sons.

Hertz, R. (1996). Introduction: Ethics, reflexivity and voice. Qualitative Sociology, 19, 3-9.

Holland, S., Williams, A., \& Forrester, D. (2013). Navigating ethical moments when researching substance misuse with parents and their children. Qualitative Research, online before print.

Holstein, J. A. \& Gubrium, J. F. (1995). The active interview. London, England: Sage Publications.

King, R. D. \& Liebling, A. (2007). Doing research in prisons. King, R.D. and Wincup, E. (Eds). Doing

Research on Crime and Justice, second edition. New York, NY: Oxford University Press.

Krieger, S. (1985). Beyond subjectivity: The use of the self in social science. Qualitative Sociology, 8, 309324.

Kruttschnitt, C. \& Gartner, R. (2003). Women's imprisonment. Crime and Justice, 30, 1-81.

Kruttschnitt, C., Gartner, R., \& Miller, A. 2000. Doing her own time? Women's responses to prison in the context of the old and the new penology. Criminology, 38, 301-337.

Liebling, A. (1999). Doing research in prisons: Breaking the silence? Theoretical Criminology, 3, 147-173.

Maruna, S. (2001). Making good: How ex-convicts reform and rebuild their lives. Washington, DC:

American Psychological Association.

Massoglia, M. \& Uggen, C. (2010). Settling down and aging out: Toward a symbolic interactionist theory of desistance and the transition to adulthood. American Journal of Sociology, 116, 543-582.

McCorkel, J. A. (1998). Going to the crackhouse: Critical space as a form of resistance in total institution and everyday life. Symbolic Interaction, 21, 227-252.

Moloney K. P., Van den bergh, B. J. \& Moller, L. F. (2009). Women in prison: The central issues of gender characteristics and trauma history. Public Health, 123, 426-430.

Moran-Ellis, J., Alexander, V. D., Cronin, A., Dickinson, M., Fieldin, J., Sleney, J., \& Thomas, H. (2006). Triangulation and integration: Processes, claims, and interpretations. Qualitative Research, 6, 45-59.

Newman, D. J. (1958). Research interviewing in prison. The Journal of Criminal Law, Criminology, and Policy Science, 49, 127-132. 
Oakes, J. M. (2002). Risks and wrongs in social science research: An evaluator's guide to the IRB.

Evaluation Review, 26, 443-479.

Pettit, B. and Western, B. (2004). Mass imprisonment and the life course: Race and class inequality in U.S. incarceration. American Sociological Review, 69, 151-169.

Pillow, W. S. (2003). Confession, catharsis, or cure? Rethinking the uses of reflexivity as methodological power in qualitative research. Qualitative Studies in Education, 16, 175-196.

Punch, M. (1994). Politics and ethics in qualitative research. Denzin, N.K. and Lincoln, Y.S. (Eds.) Handbook of Qualitative Research. Thousand Oaks, CA: Sage Publications.

Reeves, C. L. (2010). A difficult negotiation: Fieldwork relations with gatekeepers. Qualitative Research, 10, 315-331.

Schlosser, J. A. (2008). Issues in interviewing inmates: Navigating the landmines of prison research. Qualitative Inquiry, 14, 1500-1525.

Simon, J. (2000). The 'society of captives' in the era of hyperincarceration. Theoretical Criminology, 4 , 285-308.

Smith, V. (1997). Ethnography bound: Taking stock of organizational case studies. Qualitative Sociology, $20,425-435$.

Spivak, G. C. (1984-85). Criticism, feminism and the institution. Thesis Eleven, 10/11, 175-189.

Sykes, Gresham M. (1958). Society of captives. Princeton, NJ: Princeton University Press.

Tracy, S. (2010). Qualitative quality: 'Big tent' criteria for excellent qualitative research. Qualitative Inquiry, 16, 837-851.

Venkatesh, S. (2008). Gang leader for a day: A rogue sociologist takes to the street. New York: Penguin Press.

Wacquant, L. (2011). From 'public criminology' to the reflexive sociology of criminological production and consumption. British Journal of Criminology, 51, 438-448.

Waldram, J. (2009). Challenges of prison ethnography. Anthropology News, January 2009.

Ward, D. and Kassebaum, G. (1965). Women's prison: Sex and social structure. Aldine Transaction.

Warren, C. A. B. (2001). Qualitative Interviewing. Gubrium, J.F. and Holstein, J.A. (Eds.) Handbook of interview research. Thousand Oaks, CA: Sage Publications. 


\section{Contributor}

Janani Umamaheswar is an Assistant Professor in the Department of Sociology at Rider University. She recently completed her $\mathrm{PhD}$ in the Department of Sociology and Criminology at the Pennsylvania State University, and her research interests are in the areas of gender, crime and deviance, incarceration, and the life course.

\section{Footnotes}

1. There have been several interpretations of this approach, but in this study, I employed Charmaz's application of grounded theory. Charmaz (2003) noted that all variations of the grounded theory approach have certain common elements: Simultaneous data collection and analysis; the search for emerging themes during early data analysis; the search for basic social processes within the data; the inductive construction of abstract categories that explain and synthesize these social processes; sampling to refine the categories through comparative processes; and finally, the integration of categories into a theoretical framework that sheds light on the causes, conditions, and consequences of the social processes. $\subseteq$

2. An inmate also inspired my interest in this life-history approach. In her interview, Zelda suggested that I could glean valuable information by asking inmates about the most important/formative stages of their lives. $\bullet$

3. I adjusted the language slightly in the extracts from letters to facilitate readability. $\bullet$

4. Note that my status as an outsider was not highlighted only by my interaction with prison staff and officials. In the middle of one interview, a shrill, siren-like sound suddenly erupted in the building, which momentarily disoriented me. The participant I was interviewing simply stated that "it's the fire alarm" before continuing with her narrative. As such, within the prison walls, my outsider status was underscored both by prison officials' interactions with me as well as my own lack of awareness about certain features of prison life and the prison environment. 5. I replaced relatives' names with pseudonyms to protect the anonymity of inmates' identities. $\boxminus$ 